\title{
EDITORIAL
}

\section{In This Issue:}

\section{Practice Change_-Context Matters}

\author{
Kurt C. Stange, $M D, P b D$, Editor \\ Ann Fam Med 2013;11:198-199. doi:10.1370/afm.1532.
}

$\mathrm{M}$ uch of this issue of Annals and all the accompanying supplement are about changing practice.

The supplement features insights from a wide variety of practice change efforts evaluated in 14 studies on transforming primary care, supported by the US Agency for Healthcare Research and Quality (AHRQ). ${ }^{1}$ In addition to articles revealing findings from individual studies, the supplement contains an analysis of cross-cutting lessons identified by the team at AHRQ working with the investigators. ${ }^{2}$

\section{IDENTIFYING RELEVANT CONTEXTUAL FACTORS}

Innovatively, the supplement authors also identified relevant contextual factors-information important to understanding what happened and why in the study, and information that would be important to others attempting to transport the findings to a different time, place, or circumstance. These contextual factors are included as an appendix to each article in the supplement. I encourage readers to read the supplement articles, draw your conclusions about what happened and why in each study, and consider how you might apply the findings to your own circumstances. Then read the appendixes and consider how this additional information changes your interpretation and the action you might take in putting the findings into practice. For me, the results of this exercise often were shocking in how much my understanding changed in response to the additional contextual information.

In a Methodology article in the supplement, the authors and I identify categories of contextual factors that were common across their studies, and we make recommendations for others interested in enhancing the usefulness of their research by systematically considering, assessing, and reporting contextual factors. ${ }^{3}$

The Annals editors encourage researchers to consider contextual factors at the outset of their research, to engage stakeholders in assessing relevant context during the study and to report it in scholarly output. Current tenets of research rigor tend to emphasize internal validity to a greater extent than external validity. ${ }^{4}$ This imbalance means that research consumers often are blind to the situational factors that influence associations in observational research, as well as influence intervention process and outcomes in clinical trials and other experimental research. This blindness explains in part why research findings so seldom are transportable and why meta-analyses often come to such paltry conclusions - the information we need to really make sense of what is going on is seldom paid attention to, let alone reported.

\section{CHANGING PRACTICE}

Other articles in this issue of Annals (in addition to the supplement) provide a wide variety of discoveries and reflections about the process and outcome of efforts to change practice.

Culler and colleagues provide empirically derived cost estimates for the increasingly common use of facilitators to support practice change. ${ }^{5}$ An editorial by Gill and Bagley addresses the larger issue of the costs of transforming practice and who should pay for the transitional costs for the needed changes. ${ }^{6}$

In a cluster randomized trial of facilitation and learning collaboratives designed to increase colorectal cancer screening, Shaw et al discover that practice transformation requires enhanced organizational learning and change capacities that are beyond the reach of even this intensive intervention. ${ }^{7}$ In an accompanying editorial, Williams examines the underrecognized issue of assessing and reporting important variations in research in which groups, such as practices or communities, are the object of study. ${ }^{8}$

Donahue et al develop a model of the natural history of practice transformation and then test it among practices participating in the North Carolina Improv- 
ing Performance In Practice initiative. Not only do they discover a typology of the trajectories of transformed, activated, and engaged practices, but also they identify factors affecting engagement in change efforts, the rate of quality improvement, and the sustainability of changes. ${ }^{9}$

In a search for joy in practice, Sinsky and colleagues examine primary care innovations gathered from site visits to 23 high-functioning practices. Their findings highlight the potential of high-functioning teams in practice. ${ }^{10}$ An essay by Taplin also addresses the potential and challenges of team approaches to care as is being spurred by multiple movements and forces in health care. ${ }^{11}$

\section{OTHER INTERESTING RESEARCH IN THIS ISSUE}

In an innovative 3 -arm, blinded, randomized controlled trial, Rabago and colleagues examine the efficacy of prolotherapy - an injection therapy-for knee osteoarthritis. $^{12}$

Katon and colleagues prospectively examine the association of depression with risk of hypoglycemic episodes requiring either an emergency department visit or hospitalization among a large sample of people with diabetes. ${ }^{13}$ The findings call for attention to the conjoint effect of these comorbid conditions on this important outcome.

In a very interesting metasummary of qualitative studies of continuity of care, Haggerty and colleagues find that patients experience continuity as security and confidence rather than as seamlessness. ${ }^{14}$

Findings from a study of explanatory models of people attending primary care or commercial weight loss programs have implications for tailored interventions that balance patients' valuation of motivation, education, and group vs individual support. ${ }^{15}$

In a cohort study featured in Annals Journal Club, Lisman-van Leeuwen and colleagues find a surprisingly high prevalence and long duration of chronic abdominal pain among children complaining of abdominal pain in primary care. ${ }^{16}$

A study of presentations at the Society of Teachers of Family Medicine and the North American Primary Care Research Group finds that a surprising (to me at least) number or presentations become publications, and (not surprisingly) appear in a wide variety of journals. ${ }^{17}$

Finally, the Annals is delighted to announce the publication of its first book, The Wonder and the Mystery: 10 Years of Reflections from the Annals of Family Medicine. ${ }^{18}$ We are confident that you will enjoy these meaningful and well-written reflections and encourage you to consider submitting your reflections to the Annals as well.

We welcome your comments at http://www.AnnFamMed.org.

\section{References}

1. Gill JM, Cohen DJ, guest eds. Transforming primary care practice. Ann Fam Med. 2013;11(Suppl 1);S1-S123

2. McNellis RJ, Genevro JL, Meyers DS. Lessons learned from the study of primary care transformation. Ann Fam Med. 2013;11(Suppl 1):S1-S5.

3. Tomoaia-Cotisel A, Scammon DL, Waitzman N, et al. Context matters: the experience of 14 research teams in systematically reporting contextual factors important for practice change. Ann Fam Med. 2013;11(Suppl 1):S115-S123.

4. Glasgow RE, Bull SS, Gillette C, Klesges LM, Dzewaltowski DA. Behavior change intervention research in healthcare settings: a review of recent reports with emphasis on external validity. Am J Prev Med. 2002;23(1):62-69.

5. Culler SD, Parchman ML, Lozano-Romero R, et al. Cost estimates for operating a primary care practice facilitation program. Ann Fam Med. 2013;11(3):207-211.

6. Gill JM, Bagley B. Practice transformation? Opportunities and costs for primary care practices. Ann Fam Med. 2013;11(3):202-205.

7. Shaw EK, Ohman-Strickland PA, Piasecki A, et al. Effects of facilitated team meetings and learning collaboratives on colorectal cancer screening rates in primary care practices: a cluster randomized trial. Ann Fam Med. 2013;11(3):220-228.

8. Williams RL. Encouraging innovation, unintended consequences, and group-level research. Ann Fam Med. 2013;11(3):200-202.

9. Donahue KE, Newton WP, Lefebvre A, Plescia M. Natural history of practice transformation: development and initial testing of an outcomes-based model. Ann Fam Med. 2013;11(3):212-219.

10. Sinsky CA, Willard-Grace R, Schutzbank AM, Sinsky TA, Margolius $D$, Bodenheimer $T$. In search of joy in practice: a report of 23 high-functioning primary care practices. Ann Fam Med. 2013;11(3):272-278.

11. Taplin SH, Foster MK, Shortell SM. Organizational leadership for building effective health care teams. Ann Fam Med. 2013;11(3):279-281.

12. Rabago D, Patterson JJ, Mundt M, et al. Dextrose prolotherapy for knee osteoarthritis: a randomized controlled trial. Ann Fam Med. 2013;11(3):229-237.

13. Katon WJ, Young BA, Russo J, et al. Association of depression with increased risk of severe hypoglycemic episodes in patients with diabetes. Ann Fam Med. 2013;11(3):245-250.

14. Haggerty JL, Roberge D, Freeman GK, Beaulieu C. Experienced continuity of care when patients see multiple clinicians: a qualitative metasummary. Ann Fam Med. 2013;11(3):262-271.

15. Ahern AL, Boyland EJ, Jebb SA, Cohn SR. Participants' explanatory model of being overweight and their experiences of 2 weight loss interventions. Ann Fam Med. 2013;11:251-257.

16. Lisman-van Leeuwen Y, Spee LAA, Benninga MA, BiermaZeinstra SMA, Berger MY. Prognosis of abdominal pain in children in primary care-a prospective cohort study. Ann Fam Med. 2013;11:238-244.

17. Post RE, Mainous AG III, O’Hare KE, King DE, Maffei MS. Publication of research presented at STFM and NAPCRG conferences. Ann Fam Med. 2013;11(3):258-261.

18. Gotler RS. The wonder and the mystery: your voices, your stories. Ann Fam Med. 2013;11(3); 205-206. 